\title{
"LA MINIFICCIÓN NO ES EL GÉNERO PARA AQUELLOS QUE DISFRUTAN CON CARACTERÍSTICAS DEFINIDAS NI NOMBRES ESPECÍFICOS”. ENTREVISTA A VIOLETA ROJO
}

“THE MICROFICTION IS NOT A GENRE FOR THOSE WHO ENJOY WITH DEFINED CHARACTERISTICS OR SPECIFIC NAMES” INTERVIEW TO VIOLETA ROJO

\author{
Paulo Antonio Gatica Cote \\ Universidade de Santiago de Compostela \\ paulo.gatica@usc.es
}

\section{DOI: https://doi.org/10.24029/lejana.2022.15.3556}

Recibido: el 8 de noviembre de 2021

Aceptado: el 25 de noviembre de 2021

Publicado: el 25 de febrero de 2022

El propio título del presente monográfico es un claro homenaje a Violeta Rojo (Caracas, 1959), una de las figuras más representativas dentro de los estudios de las formas breves. ${ }^{1} \mathrm{La}$ semblanza de la eminente especialista es de sobra conocida: profesora titular e investigadora del Departamento de Lengua y Literatura de la Universidad Simón Bolívar. Doctora en Letras por dicha universidad en 2000. Profesora visitante en varias instituciones internacionales y autora de iluminadores trabajos y ensayos sobre literatura venezolana contemporánea (Las heridas de la literatura venezolana y otros ensayos, El Estilete, 2018) y sobre el escurridizo campo de la microtextualidad. En esta línea, sobresalen las antologías La minificción en Venezuela (Universidad Pedagógica Nacional, 2004) y Mínima Expresión. Una muestra de la minificción venezolana (Fundación para la Cultura Urbana, 2009), el ensayo Liberándose de la tiranía de los géneros y otros ensayos sobre minificción (Micrópolis, 2015) y, en mi opinión, una de las principales monografías publicadas sobre minificción: Breve manual para reconocer minicuentos (Fundarte-Equinoccio, 1996; 2a edición ampliada Equinoccio, 2009). En 2020 apareció su última incursión en esta materia: La minificción ya no es lo que era (El Taller Blanco Ediciones, 2020).

\footnotetext{
${ }^{1}$ Este trabajo fue realizado durante el período de disfrute de una Ayuda Juan de la Cierva Incorporación (IJC2020044411-I) financiada por MCIN/AEI/10.13039/501100011033 y por la Unión Europea NextGenerationEU/PRTR. El artículo forma parte de las actividades del proyecto de investigación PERFORMA2. Metamorfosis del espectador en el teatro español actual (PID2019-104402RB-I00) (2020-2023), financiado con una ayuda del Ministerio de Ciencia e Innovación en el marco del Plan Estatal de Investigación Científica y Técnica y de Innovación 2017-2020.
} 
Paulo Antonio Gatica Cote: Antes de empezar, he de agradecer su excelente disposición a responder cuestiones que, seguramente, ya le habrán planteado de un modo más lúcido o que se alejan de sus intereses. Quizá por esto creo que una buena manera de comenzar sería por el final: ¿qué fenómenos o aspectos del minicuento/minificción actual le llaman más la atención?

Violeta Rojo: Me gusta mucho ver que cada vez hay más publicaciones académicas, más revistas especializadas, más investigadores y más teorías y líneas de investigación sobre el tema. Siento que cuando comenzamos era posible leer todo lo publicado sobre la minificción, mientras que ahora es totalmente imposible. No solo la magnitud de enfoques y de artículos, sino también los muchos idiomas en los que se analiza. Es muy emocionante ver crecer un tema de investigación, constatar nuevas teorías y acercamientos, comprobar cómo crece un campo intelectual.

Por supuesto, la cantidad también es un problema, específicamente en el corpus a analizar. Aunque hay excelentes textos y magníficos libros, la verdad es que, a veces, la repetición de fórmulas, la falta de densidad literaria, la superficialidad, el chistecito y demás tonterías me molestan mucho. Siento que ahora hay tanta cantidad que me cuesta mucho encontrar joyas (que por supuesto que hay) entre tanto follaje.

Por supuesto, eso es habitual en todas las artes, géneros y estudios, pero creo que extraño un poquito la época de descubrimiento.

P. A. G. C.: La cuestión terminológica (minicuento, microrrelato, microficción, minificción...) ha protagonizado en muchos trabajos y encuentros buena parte de las discusiones. ¿Podría explicar por qué optó en aquel trabajo de 1996 por el término minicuento? ¿Sigue siendo un concepto operativo para el estudio de la microtextualidad literaria en el actual ecosistema cultural?

V. R.: En aquel momento consideraba que era un cuento pequeño y mi teoría era para demostrar eso. Con tu pregunta me doy cuenta de que yo misma me contradije en el Breve manual... Si es cuento no puede ser des-generado y el des-género me sigue pareciendo válido. Debí llamarlo minificción desde el origen, pero no sé si en esa época se usaba el término.

Ahora no creo que sea un cuento, aunque puede serlo. Por los momentos lo considero una forma de literatura mínima y ficcional. Pero esa es mi opinión. Hay magníficos trabajos que demuestran que sí, que es un cuento; o que el relato es fundamental. Lo bueno de la teoría literaria es que, si está bien fundamentada se puede estar en desacuerdo, pero al mismo tiempo admirar, o no, el proceso argumentativo.

Dado que considero que la minificción no es posible de definir fácilmente (como todos los géneros literarios en el siglo XXI, por cierto) me parece que la cantidad de términos con que se la denota es parte de esa indeterminación; por tanto, me gusta que los nombres sean diferentes. La minificción no es el género para aquellos que disfrutan con características definidas ni nombres específicos, sigo pensando que encasillarlo es imposible. Pero eso también tiene que ver con mi acercamiento intelectual. No me gustan los compartimientos; creo que no son posibles y que siempre se salen aspectos por los lados, o no cuadran, o se trata de forzar el 
enfoque para que cuadre con la realidad, siempre terca, que insiste en ser lo que es y no plegarse al esquema que se le asigna.

P. A. G. C.: En relación con la pregunta anterior, querría citar el primer párrafo de la introducción de su libro La minificción ya no es lo que era: "Mientras más estudio la minificción, menos certezas tengo sobre el género. Si alguna vez consideré que podía teorizar sobre sus características y orígenes, ahora tengo muchas dudas y solo estoy segura de que es una forma literaria muy breve”. ¿A qué se debe esta indeterminación? Si ha perdido sentido la discusión acerca de las posibles características y tipología del género, ¿cuáles serían o deberían ser las zonas oscuras que necesitan una mayor atención?

V. R.: Esa es una confesión personal, no tiene necesariamente que ver con el género sino con mi abordaje. La verdad es que mientras más estudio de cualquier cosa, más dudas tengo, porque veo más matices, variantes y diferencias. En suma, mi acercamiento intelectual es desde la falta de certezas y, cuando analizo más, me doy cuenta de que son menos las características que se repiten y más las diferencias. Eso lo puedo aplicar a la minificción, las religiones, el gazpacho o la escultura. Nada es exactamente de una manera sino de muchas, y justamente esa variedad, esa imposibilidad de poner en un molde específico algo, es lo que me fascina. Me parece inane la alegría de la clasificación rígida, porque una vez que encasillas algo vivo no puedes ver cómo crece y cambia, lo conviertes en algo baldío. En cambio, el comprender que lo que produce el ser humano puede ser analizado y descrito, pero que la prescripción es vana, es una manera de dejar que esas producciones sigan vivas. Supongo que es como los bonsáis o los setos recortados: son bonitos, pero a mí no me gustan.

Por supuesto, me parece interesante que los demás tengan certidumbres donde yo no veo sino dudas, así que cualquier estudio que se haga me parece bien. Creo que también tiene que ver con que las teorías (literarias, filosóficas, sociológicas, políticas, etc.) en general me parecen constructos intelectuales. Siempre son interesantes; es toda una experiencia desarrollarlas, pero no son verdades absolutas.

Una vez escuché a dos biólogos hablando con gran emoción de que se había descubierto un insecto cuyas antenas tenían tres segmentos y no los dos que se conocían hasta el momento, lo que tumbaba muchas teorías sobre lo que sea que impliquen las antenas de los insectos. Si eso sucede con biología, imagínate lo que puede pasar con las expresiones de un género literario que cambia de acuerdo a quien lo desarrolle.

P. A. G. C.: En torno a géneros como el aforismo o el cuento, se ha señalado en más de una ocasión la existencia de una especial relación entre propuestas teóricas y creativas. De hecho, no resulta extraña la coincidencia de ambos roles. ¿Qué puede aportar la teoría a la creación? ¿Hay una sobredosis teórica?

V. R.: ¿Para qué ha de leer un narrador a un teórico? Es al contrario. Los narradores son creadores de mundos, y no deberían tener que circunscribirse a propuestas teóricas o académicas. Y eso se aplica a cualquiera de las ramas del arte. Imagínate si se siguiera pintando 
de acuerdo a los parámetros de los academicistas o el arte debería ser como dijo Tristán Tzara, o se considerara que la música debe seguir siendo heterofónica porque así dijo Platón que debería ser. Hay quienes consideran que hay que conocer las teorías para romper los moldes, pero tampoco estoy muy segura.

En todo caso, las teorías siempre han existido y son fundamentales para el conocimiento en todas las ramas del saber, pero eso no quiere decir que sean inmutables. Si genios como Aristóteles, Freud o Giordano Bruno hicieron planteamientos que ahora sabemos que no eran totalmente correctos, imagínate lo que nos queda a los demás. Supongo que hay grandes narradores con conocimientos teóricos de la literatura, pero no sé si ese conocimiento es necesario para escribir ficción. La teoría es fundamental para el análisis literario y para la docencia, pero eso es otra cosa.

P. A. G. C.: Sobre la base de las intuiciones de Italo Calvino y otros especialistas, se ha extendido con relativo éxito la opinión de que el microrrelato es el género por excelencia del siglo XXI. También he llegado a leer esta misma afirmación referida al aforismo. En este sentido, se menciona la influencia de las TIC en casi cualquier reflexión sobre un supuesto boom de las formas breves, ya sea para justificar la mayor difusión y cultivo o para valorar su impronta textual: hibridaciones discursivas, relaciones texto-imagen, paratextualidad, etc. ¿Comparte este diagnóstico o percibe una sobredimensión del fenómeno? Si efectivamente existe dicho boom, ¿qué factores intervienen y en qué se manifiesta?

V. R.: La literatura breve existe, con formas diferentes, desde hace cientos de años. La forma, tal como la conocemos ahora, ha tenido diferentes auges: los experimentalistas de principios del siglo XX, luego en los años 50, más tarde en los 70, hubo un auge teórico en los años 90 del siglo pasado. Lo que pasa es que hay gente que lo descubre ahora y piensa que acaba de aparecer. Las redes sociales han divulgado mucho el género, lo han abaratado en algunos casos $\mathrm{y}$, peor aún, han hecho pensar que cualquier tontería en un tuit es un texto literario. Pues no, la minificción es literatura y requiere talento y dedicación a la palabra.

No creo en los booms, ni creo que la minificción sea el género perfecto para las redes sociales, ni que ahora tenemos menos tiempo y la literatura debe ser breve. ¿Tenemos menos tiempo? No sé, a mí me sigue encantando leer libros larguísimos. Lo que veo en cultura popular (películas, series de TV, libros, videojuegos) son más bien sagas, epopeyas y series narrativas, no minificciones. Tampoco es que vea las librerías cundidas de libros de minificción porque sea el género del milenio.

Hace décadas, un periódico venezolano publicó una antología de minificciones muy buena que se llamaba Para leer en la cola. Se referían al tráfico venezolano, la idea era que mientras esperabas el semáforo podías leer una minificción. No puedo imaginarme algo más espantoso que leer rapidito mientras cambia la luz, sin atención ni profundidad. Trata de hacer eso con los aforismos de Humano, demasiado humano de Nietzsche a ver qué tal.

En fin, ni creo que todo este milenio (casi nada, mil años) tendrá literatura parecida, ni me parece que las características de Calvino sean aplicables a todo, pero sobre todo no creo que ningún género sea el adecuado para ningún siglo. 
Me preocupa un poco que se considere que las RRSS determinan tanto. Quizás dentro de 20 años no habrá redes sociales, sino otra cosa totalmente distinta. Siempre hay cosas nuevas que se supone que van a acabar con las antiguas: el cine iba a acabar con el teatro, la televisión con el cine, las redes sociales con la literatura, el eBook con el libro en papel, internet con la vida social, pero apartando eventos terribles como la pandemia, se siguen vendiendo más libros de papel; el teatro, el cine, la TV y las plataformas conviven y pocas cosas desaparecen.

P. A. G. C.: En su opinión, ¿cuál es el estado del minicuento en Venezuela? Como antóloga, ¿cuáles fueron los principales desafios a los que se enfrentó durante su confección? Supongo que desde su publicación habrán surgido voces inéditas. ¿Publicará una nueva edición de la antología? ¿Podría recomendarnos algunos creadores?

\section{R.: Ay.}

Venezuela sufre una dictadura terrible desde hace ya muchos años. Además de los habituales horrores (censura, torturas, asesinatos, represión, diáspora) tenemos hiperinflación y una crisis humanitaria compleja. Eso ha dificultado la vida cultural venezolana, aunque consideramos que es un acto de resistencia continuar escribiendo y publicando, pero no es nada fácil.

No sé por qué, la minificción ha sufrido una merma importante en estos años. Supongo que es porque no es un género comercial y a las editoriales se les dificulta mucho decidir invertir en publicarlo.

Mínima expresión fue una experiencia muy interesante, pero ya tiene más de diez años. Mi idea no era hacer una antología sino una muestra, o sea, dar a conocer las diferentes voces de la literatura brevísima venezolana. Como suele suceder, no incluí a gente que descubrí después, revistas que no conocía y muy buenos escritores en los que no había reparado. Creo que me gustó mucho descubrir al Fraile Navarrete, que en el siglo XIX ya escribía literatura breve.

Me encantaría poder hacer una nueva edición en la que agregara autores, pero con lo que te comenté antes no lo veo fácil.

Prefiero no recomendar a nadie, porque mañana recordaré a una docena que no nombré, pero sí creo que la minificción venezolana debería ser más leída y reconocida.

P. A. G. C.: Sin duda, una de las expresiones más evidentes del auge de la minificción en el ámbito hispánico es la consolidación de un mercado literario propio (editoriales especializadas, amplia oferta y demanda de títulos, numerosos premios, presencia destacada en revistas, etc.). Me gustaría compartir con usted una inquietud creciente, que me han trasladado no pocas personas que se dedican a la brevedad: ¿se publican demasiadas antologías? ¿Goza de (tan) buena salud (como parece) la minificción o podría morir de éxito?

V. R.: No sé si los géneros gozan de buena salud o mueren, pero espero que ese abaratamiento no le haga más daño aún. Aunque la poesía ha sufrido los mismos desmanes y sigue ahí, regia 
y magnífica a pesar de los concursos de reconocidas editoriales en los que premian a "poetas" según su número de seguidores en las RRSS.

Quizás esa pregunta es aplicable a todo. ¿La fotografía morirá de éxito porque ahora todos tenemos una cámara en el celular? Para no repetirme, en el 2010 llevé una ponencia al Congreso Internacional de Minificción de Bogotá sobre el tema, se publicó como "Atrapados en la red. La banalización de la escritura mínima", y ya en ese momento mostraba mi desconcierto por este asunto. Pero creo que lo fundamental es que no creo que sea un género de moda, ni que tenga tan buena salud, etc. Si nos vamos a las cifras (número de editoriales y revistas especializadas, tiraje y cantidad de títulos) la minificción sigue siendo marginal.

Tampoco creo que se publiquen demasiadas antologías en ningún género. El equilibrio entre dejar que la escritura se publique y difunda y los criterios de calidad es algo difícil. ¿Quién es el censor que decide que hay muchas publicaciones y que deberían eliminarse? Y, por supuesto, ¿de verdad sabemos qué tiene calidad y qué no? ¿Eso no varía con el tiempo? ¿Estamos seguros de que con el paso del tiempo no vamos a descubrir joyas que en su momento no leímos adecuadamente? Sí, tenemos una oferta impresionante, pero lo mismo sucede con todo y más o menos nos manejamos perdiendo los cientos de libros, películas, series, óperas, conciertos y eventos a los que no podemos acceder porque no hay tiempo.

P. A. G. C.: Por otro lado, los talleres literarios y, sobre todo, la multiplicación de espacios y redes nacidos en la web juegan un papel protagonista en la aparición de un tipo de lector curioso que, además de iniciarse en la escritura, desea publicar sus primeros trabajos incluso al margen de filtros y agentes tradicionales. Ante este panorama, ¿cuál debería ser la función de la crítica?

V. R. Creo que la crítica en el sentido de análisis es importante, pero la reseña que juzga no me interesa y ni siquiera la leo. Es imposible que quienes se dedican a la crítica puedan estar al tanto de todo lo que se publica por los canales regulares, mucho menos fuera de estos. En un mundo perfecto la gente sabría qué es mejor gracias a la educación, pero eso no funciona así en ningún país y en ninguna época. Es más, en los medios convencionales veo más reseñas sobre libros comerciales que sobre muy buenos libros que no reciben ni una mención.

P. A. G. C.: Entre otras razones, se reivindica la utilidad del minicuento o de la minificción para el fomento de la lectura y para la enseñanza de la lengua y de la literatura porque conjugan una gran concentración de recursos y efectos con unas dimensiones "asumibles". Desde su perspectiva como docente, ¿comparte esta apreciación? ¿Cuál es su experiencia en las aulas?

V. R.: Las minificciones son difíciles de leer, ya sea porque tienen cantidad de elementos intertextuales o porque tienen juegos retóricos para conseguir la brevedad, todo lo cual hace que necesiten un lector atento e informado. En La lectura de minificción analizo "La discípula" de Herbert Allen Giles y tuve que leer mucho sobre sinología y mandarín para comprender 
algunas de las muchas lecturas que se pueden hacer sobre ese texto, que son numerosas, complejas y yo simplemente las medio vislumbré.

Es verdad que pareciera que algo tan corto puede ser atractivo para los estudiantes, pero para mí es un género muy complejo, que requiere manejar la estética y en algunos casos la ironía, la parodia y la intertextualidad.

Ana María Shua dice que leer minificción es parecido a comer bombones: debe hacerse con moderación. Efectivamente, cada uno de esos pequeños textos es un mundo diferente, amplio y complejo. Sumergirse en cada uno necesita cultura, análisis y reflexión. Que sean cortos no significa que sean más fáciles, sino todo lo contrario. Y si son difíciles de comprender, más difíciles aún son de escribir.

Mi experiencia fue muy diferente. Solo di un curso de minificción para estudiantes no especializados y me fue dificilísimo. Pero ahí me rindo a la evidencia: mucha gente amiga estudia y utiliza la minificción para estimular la lectura, así que supongo que el problema es mío.

P. A. G. C.: Aun a riesgo de abusar de su amabilidad y paciencia, me gustaría remontarme a un hipotético origen para cerrar la entrevista: ¿cuándo, cómo y por qué surgió el interés -o la necesidad - por el estudio del minicuento? ¿Recuerda cuáles fueron sus principales lecturas de creación y sus referentes teóricos en aquel momento?

V. R.: Hace más de treinta años, cuando estudiaba la maestría, en un curso de teoría del cuento pregunté sobre la teoría de la minificción. El profesor me dijo que ese podría ser un interesante tema de investigación para mí. Efectivamente, fue un tema de investigación que no se agota, aunque yo sí me siento agotada. Tengo otros temas de investigación, ahora me dedico más a la narrativa venezolana del siglo XXI y a las escritoras, después de pasar por literatura autorreferencial, historia y ficción y biografías, entre otros temas. Sin embargo, sigo estando pendiente y participando en foros, encuentros y grupos.

En cuanto a los referentes, de antes y de ahora, los principales han sido también gente amiga: Pía Barros, Raúl Brasca, Guillermo Bustamante Zamudio, Stella Maris Colombo, Luis Armando Epple, Gabriela Espinosa, Agustín Monsreal, Francisca Noguerol, Javier Perucho, Laura Pollastri, Ana María Shua, Graciela Tomassini, Laura Elisa Vizcaíno, Lauro Zavala y, entre los que ya no están con nosotros, Henry González, David Lagmanovich y la queridísima Dolores Koch. Lolita no fue solo la abanderada de los estudios de minificción y una referencia teórica y analítica imprescindible, sino también una querida amiga que me enseñó muchas cosas y a la que sigo extrañando.

Quisiera terminar agradeciéndote tus preguntas, tan serias y rigurosas, que me han hecho reflexionar mucho, darme cuenta de mis errores conceptuales y abrirme panoramas que no había tenido en cuenta. Todavía queda mucho por hacer. 
(C) Paulo Antonio Gatica Cote

(C) Violeta Rojo

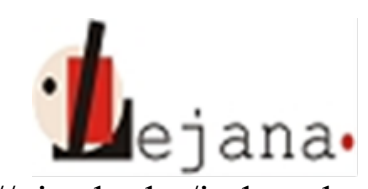

http://ojs.elte.hu/index.php/lejana

Universidad Eötvös Loránd, Departamento de Estudios Hispánicos

1088 Budapest, Múzeum krt. 4/C 